\title{
Some Phenomena Related to the Strain Age Hardening of Carbon Steel*
}

\author{
By Kazuyoshi Nishino**
}

\begin{abstract}
The secondary strain age hardening of carbon steels observed by annealing above $150^{\circ} \mathrm{C}$ is accompanied by the following peculiar phenomena. (1) A slight rolling after strain age hardening treatment of cold rolled steels induces work sof tening as in the case of $\alpha$-brass. (2) A slight application of cold working different in mode from the primary working to cold worked steels brings about a hardening, say, secondary work hardening as in the case of $\alpha$-brass, and it is presumed that the increase in hardness is induced not only by low temperature annealing but by mechanical treatment, and that it concerns a dislocationdislacation interaction. (3) Quenched and tempered. carbon steels soften by slight cold working, the softening being probably the same in kind. as the work softening stated above. It is inferred that cementite particles act as obstacles against dislocation, and pile-up dislocations around them cause back stresses, by which the Bauschinger effect becomes marked, and that the secondary strain age hardening is brought about by the prevention of motion back of the dislocation under the influence of the back stress. One possible mechanism of the prevention is such that dislocations in pile-up groups move back and encounter other groups with which they react, losing their mobility. Such an interaction of intersecting dislocations may be the easier and the larger the denser the groups. From the fact that the strain age hardening above $150^{\circ} \mathrm{C}$ of carbon steels is closely similar to that of $\alpha$-brass in many respects, both hardenings are considered to be the same in cause. However, they are dissimilar only in that in the former the cementite particles act as an obstacle agajnst dislocation, while in the latter such an obstacle is introduced during deformation.
\end{abstract}

(Received May 31, 1961)

\section{Introduction}

The secondary strain age hardening of carbon steel in the range of $150-350^{\circ} \mathrm{C}$ is closely similar to that of $\alpha$-brass. However, the latter is a change within a simple solid solution, while the former is related to the dispersion of the cementite particles as an obstacle against dislocations. Thus, it may be important to study the relation of the hardenings of both alloys for the elucidation of their nature.

When a cold drawn carbon steel is slightly extended after annealing at $300^{\circ} \mathrm{C}$, it lbecomes tough (1). Also, a slight application of tensile stress to compressed steel brings about a softening ${ }^{(2)}$. Carbon steel exhibits such peculiar phenomena. As stated previously, $\alpha$ -

** The Research Institute for Iron, Steel and Other Metals, Tchoku University, Katahira-cho, Sendai, Japan.

* This paper was published in Japanese in the Joural of the Japan Institute of Metals, 24 (1960), 518.

(1) K. Takahashi and H. Suemitsu : Sect. Rep. Japan Inst. Metals, IX (1952). (In Japanese.)

(2) N. H. Polakowski: J. Iron Steel Inst., 169 (1951), 337. brass in a work hardened or strain age hardened state shows various peculiar phenomena such as work softening or secondary work hardening when an external stress is applied ${ }^{(3)}$ : Thus, the author wanted first to study the principle of the secondary strain age hardening of carbon steel and to clarify these phenomena and make a comparison of the characteristics of carbon steel with those of $\alpha$-brass.

The method of measuring the thermoelectric force consisted of a couple formed by the drawn wire to be studied and a reference wire of the same steel in an unworked state. The thermoelectric force between $0^{\circ}$ and $60^{\circ} \mathrm{C}$ was measured with a sensitive galvanometer. Low temperature annealing of the wires was: performed by immersion for 5 minutes in oil and $\mathrm{Pb}-\mathrm{Sn}$ baths at the desired temperatures. The other experiments and carbon steels used were the same as

(3) K. Nishino: J. Japan Inst. Metals, 20 (1956), 115, 704; 22 (1958), $50 ; 23$ (1959), 232, 236. 
those described by the author in a previous paper.

\section{Results}

\section{Work softening}

Fig. 1 shows the work softening. When a slight working of the same mode and in the same direction as those of prior working is applied after low tempera-

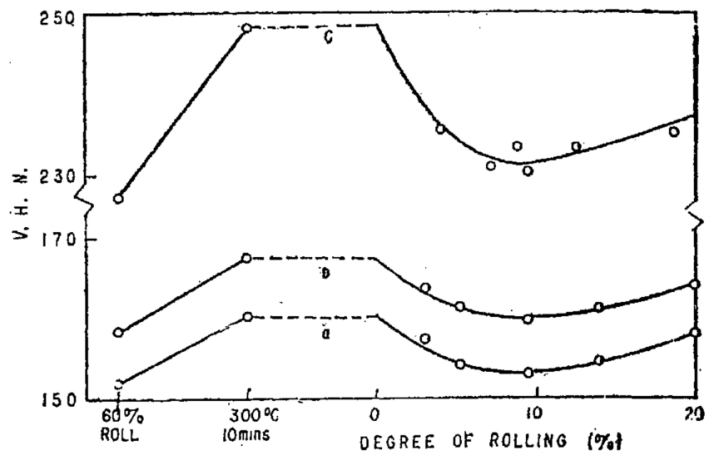

Fig. 1 Work softening curves of carbon steels.

$$
\begin{aligned}
& \mathrm{a}: 0.02 \% \mathrm{C} \text { stsel } \\
& \mathrm{b}: 0.12 \% \mathrm{C} \text { steel } \\
& \mathrm{c}: 0.50 \% \mathrm{C} \text { steel }
\end{aligned}
$$

ture annealing, a softening occurs similarly to the case of $\alpha$-brass ${ }^{(3)}$. It may, therefore, be considered that by such a slight application a strain age hardened specimen is forced to come back to the state before low temperature annealing. As shown in Fig. 2, the Bauschinger effect becomes marked again by a slight

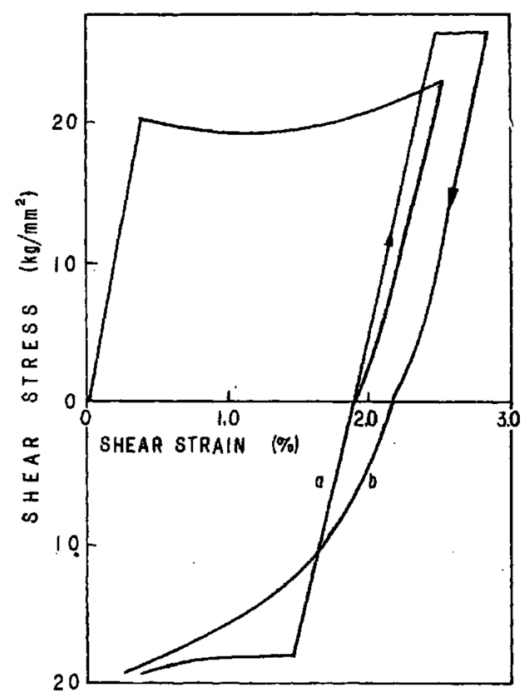

Fig. 2 Torsion stress strain diagram of $0.9 \% \mathrm{C}$ steel.

secondary working. Namely, when low temperature annealing is made after the prior torsion, the effect is removed (curve a), but when a specimen is re-twisted in the direction of prior torsion after low temperature annealing, it again becomes pronounced (curve b).

Figs. 3 and 4 show the results of the thermoelectric force. Although thermoelectric force is a rather complicated property, it is convenient for examining the effect of conditions of cold working, particularly of the secondary working, since it does not need to control the sectional area of the specimen unlike the electrical resistance. In $\alpha$ brass $^{(3)}$, it was found that the thermoelectric force behaved similarly to the electrical resistance.
As shown by curve (a) in Fig. 3, the thermoelectric force of $0.5 \% \mathrm{C}$ steel increases steeply in the first $15 \%$ of rolling unlike $\alpha$-brass, in which it increases sharply beyond $15 \%$ rolling( ${ }^{(3)}$. Such behaviors in $\alpha$-brass and carbon steel are in good agreement with those of the strain age hardening. The thermoelectric force decreases in two stages with low temperature annealing, and the effect of cold working is

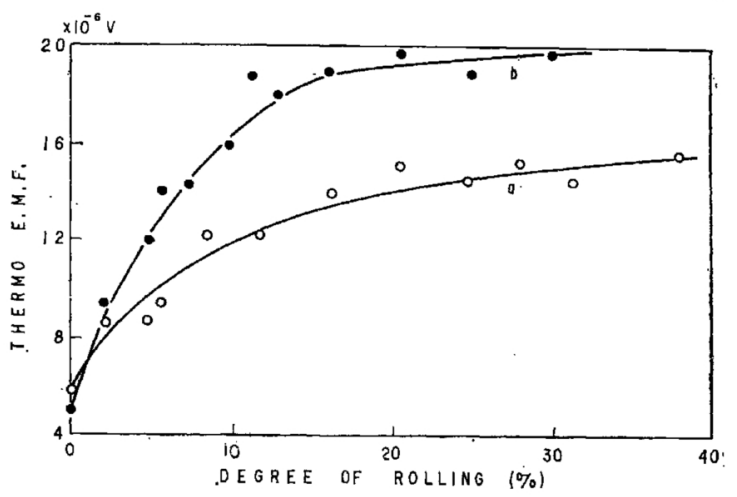

Fig. 3 Thermoelectric force $\left(0\right.$ to $\left.60^{\circ} \mathrm{C}\right)$ and rolling degree of $0.5 \% \mathrm{C}$ steel.

a : Untreated

b: Annealed at $350^{\circ} \mathrm{C}$ for 5 minutes after $60 \%$ rolling

almost removed by annealing at about $300^{\circ} \mathrm{C}$ (curve (a) in Fig. 4). In addition, by slight working (about $10 \%$ rolling) after $350^{\circ} \mathrm{C}$ annealing, the thermoelectric force returns completely up to the value

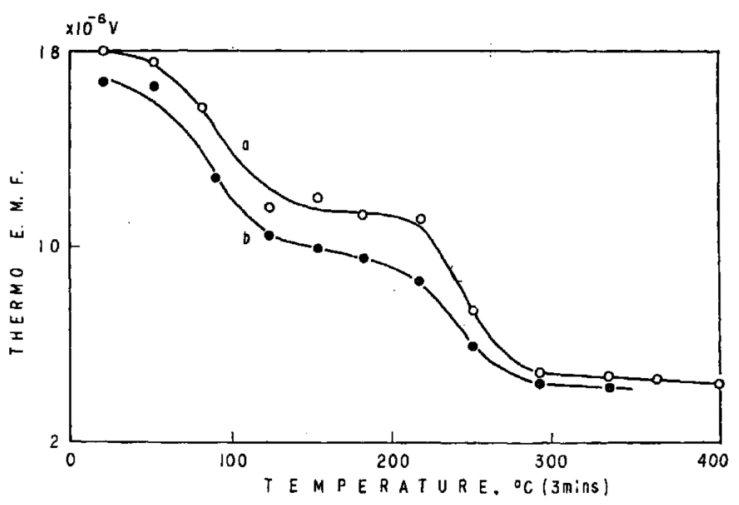

Fig. 4 Change in thermoelectric force $\left(0\right.$ to $\left.60^{\circ} \mathrm{C}\right)$ with annealing temperature of $0.5 \% \mathrm{C}$ steel.

a : $62 \%$ rolled

b : $62 \%$ rolled, and then $8 \%$ rolled after annealing at $350^{\circ} \mathrm{C}$ for 5 minutes.

before low temperature annealing (curve (b) in Fig. 3), and it behaves during re-annealing in a similar manner. to the primary annealing (curve (b) in Fig. 4.). On the other hand, in $\alpha$-brass the thermoelectric force did not return to the original value by such secondary working, although the hardness $\operatorname{did}^{(3)}$. It may be necessary for interpretation of the results stated above to elucidate the difference of carbon steel and $\alpha$ brass in the respects that in the former the recovery of thermoelectric force related with the recrystallization is absent, while in the latter it is remarkable ${ }^{(3)}$.

\section{Secondary work hardening}

When a secondary working differing in mode from the primary is made, the change of hardness is more complicated than in the case when the both workings 
are the same.

In Fig. 5 is shown the relation of the rolling degree and the hardness for severely drawn specimens of carbon steel. Here, the rolling was performed in the direction of the specimen axis, and the hardness was measured on the plane parallel to the roll. With the progress of such a different mode-secondary working, specimens of higher carbon steels first hardened and

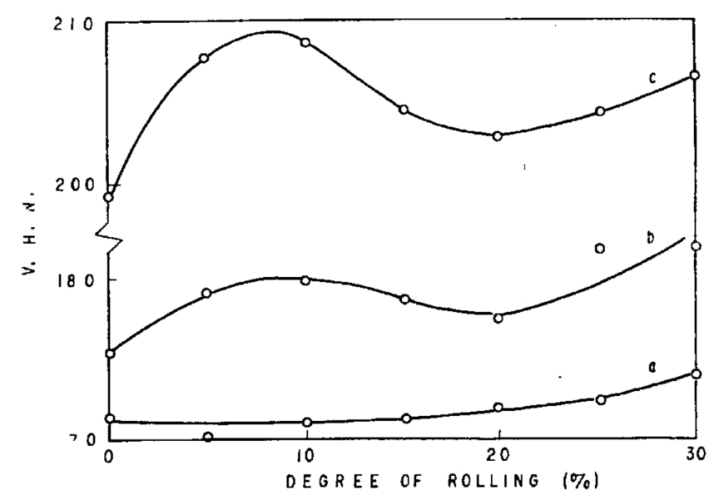

Fig. 5 Degree of rolling and hardness of carbon steel drawn to $64 \%$ reduction.

a : $0.02 \% \mathrm{C}$ steel

b : $0.28 \% \mathrm{C}$ steel

c : $0.50 \%$ C steel

then softened, and the trend is almost similar to that of $\alpha$-brass ${ }^{(3)}$. This hardening, i.e., secondary work hardening, seems to be prominent in such alloys showing marked strain age hardening, and it is also
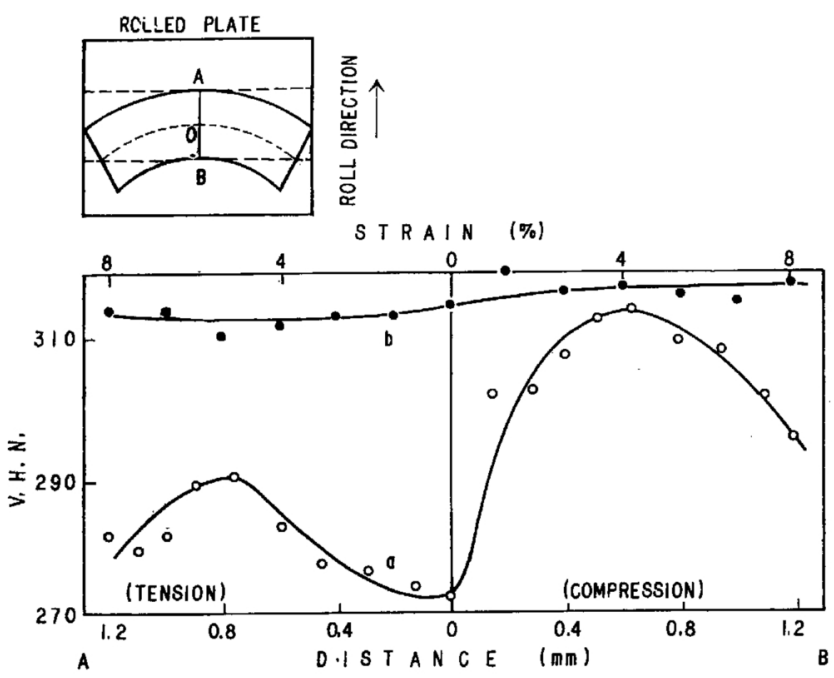

Fig. 6 Hardness changes by bending of $0.9 \% \mathrm{C}$ steel cold rolled to $37 \%$ reduction.

a : Rolled and bent

b : Rolled, bent and then annealed at $320^{\circ} \mathrm{C}$ for 5 mins.

induced by combining tensile and compressive deformations ${ }^{(3)}$. Fig. 6 also shows the secondary work hardening of a cold rolled $0.9 \% \mathrm{C}$ steel by slight bending. Bending was made on a specimen as shown at the upper part of Fig. 6, and the hardness was measured in the range of the length of $A B$ on the plane parallel to the roll, so that the hardness in the as-primary-worked state showed a uniform distribution within this range. The secondary work hardening and the subsequent softening are also observed and the change in hardness is much larger than that in the case of Fig. 5. In addition, it will be noted from Fig. 6 that the secondary work hardening is markedly larger on the compression side than on the tension side (curve (a)), its degree being largely affected by the work condition, and more when a bent specimen is annealed at $320^{\circ} \mathrm{C}$ (curve (b)), the hardness rises nearly up to the maximum value on curve (a) and it gains again a uniform distribution throughout the section.

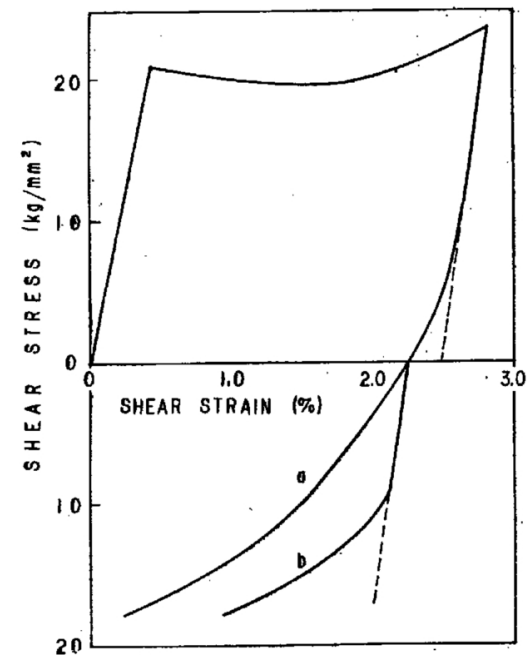

Fig. 7 Torsion stress strain diagram of $0.9 \% \mathrm{C}$ steel

$$
\begin{aligned}
& \text { a : Untreated } \\
& \text { b: } 0.7 \% \text { extended }
\end{aligned}
$$

Also in $\alpha$-brass, a closely similar change was observed, but with lower carbon steels, such a change in hardness is much less marked.

As shown in Fig. 7, the Bauschinger effect decreases by a slight application of the secondary working stated above. Namely, when a specimen is first twisted and then re-twisted in the reverse direction, it shows a marked Bauschinger effect (curve (a)), but by a slight tensile working $(0.7 \%$ strain) before re-twisting, it gains elasticity in the reverse direction (curve (b)),

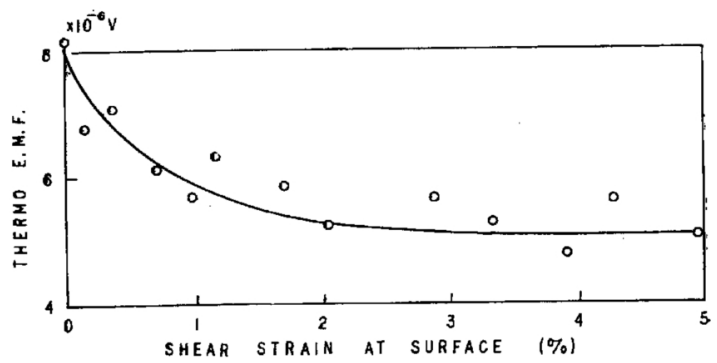

Fig. 8 Thermo electric force $\left(0\right.$ to $\left.20^{\circ} \mathrm{C}\right)$ and shear strain of $0.6 \% \mathrm{C}$ steel previously $55 \%$ drawn.

the recovery being likely to correspond to the secondary work hardening. As this intermediate tensile working proceeds, the recovery first occurs steeply, but its rate becomes progressively smaller beyond a certain degree, about 2 to $5 \%$ tension, it varying to some extent with the degree of prior working.

In Fig. 8 is shown the change of thermoelectric force by torsion for $55 \%$ drawn specimens of a 0.6 $\% \mathrm{C}$ steel. The thermoelectric force decreases as the secondary working proceeds, showing that the secondary working acts exactly in the direction to relieve the effect of primary working similarly to the 
case of the Bauschinger effect.

On further secondary working after the secondary work hardening, a softening occurs as shown in Fig. 5 and also by curve (a) in Fig. 6 . In $\alpha$-brass ${ }^{(3)}$, when the primary working is made severely, the degree of secondary work hardening is nearly identical to that of softening. Also in the case of carbon steels it is appoximately similar. It is, thus, likely that when the primary or secondary working is severe, "inelastic structure", in any case, peculiar to the mode of cold working is obtained, it being in a softened state, and that the intermediate stage where the as-primaryworked structure transforms to the secondary is not inelastic, it being in a hardened state. Here, "inelastic structure" means a structure exhibiting an inelastic effect, and is considered to concern a distribution of pile-up dislocations as stated later.

Fig. 9 shows the changes in hardness of a Cu-8 \% Al alloy and a $0.9 \% \mathrm{C}$ steel in which the strain age
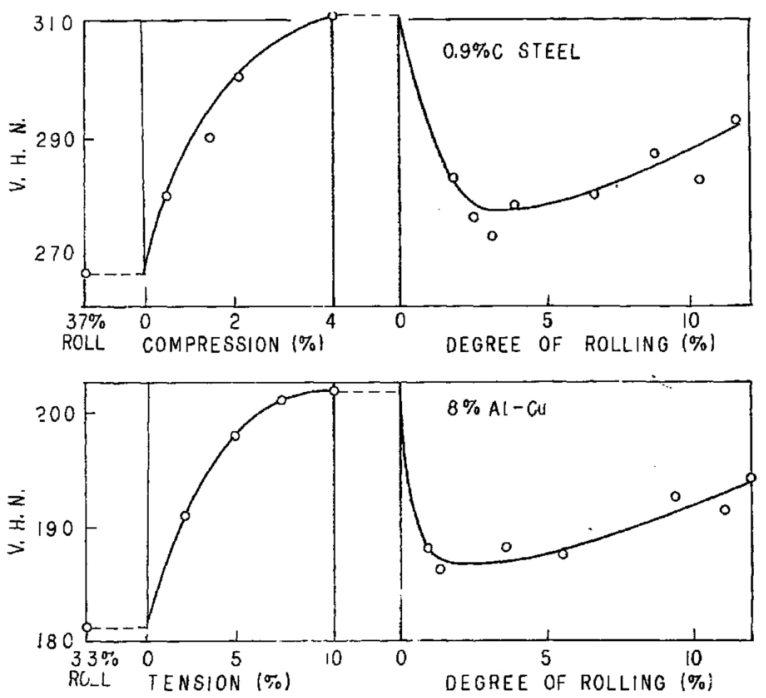

Fig. 9 Effect of secondary working on hardness.

hardening is remarkable. When the specimens were secondly cold worked in a different mode from the primary rolling, they hardened conspicously beyond expectation from work hardening, and thereafter softened by a slight working of the same mode as that of the primary working. Here, in the carbon steel the compressive stress applied secondly was obtained by bending as in the case of Fig. 6. It may be allowable to say that the softening above stated is of the same kind as the work softening after the strain age hardening treatment (Fig. 1), and that the different mode-secondary working made after primary rolling gives an effect similar to low temperature annealing, and further that the increase in hardness can be obtained not only by low temperature annealing but by mechanical treatment. Thus, the strain age hardening and the secondary work hardening may be induced by a similar cause, i.e., by a disappearance in the "inelastic structure". They are dissimilar only in that in the former the disappearance is induced thermally, while in the latter it is caused by forced deformation.

3. Work softening of quenched and tempered

\section{steel}

In Fig. 10 are shown the hardness-rolling degree curves for a $0.9 \% \mathrm{C}$ steel quenched from $800^{\circ} \mathrm{C}$ and tempered at the illustrated temperatures. The work

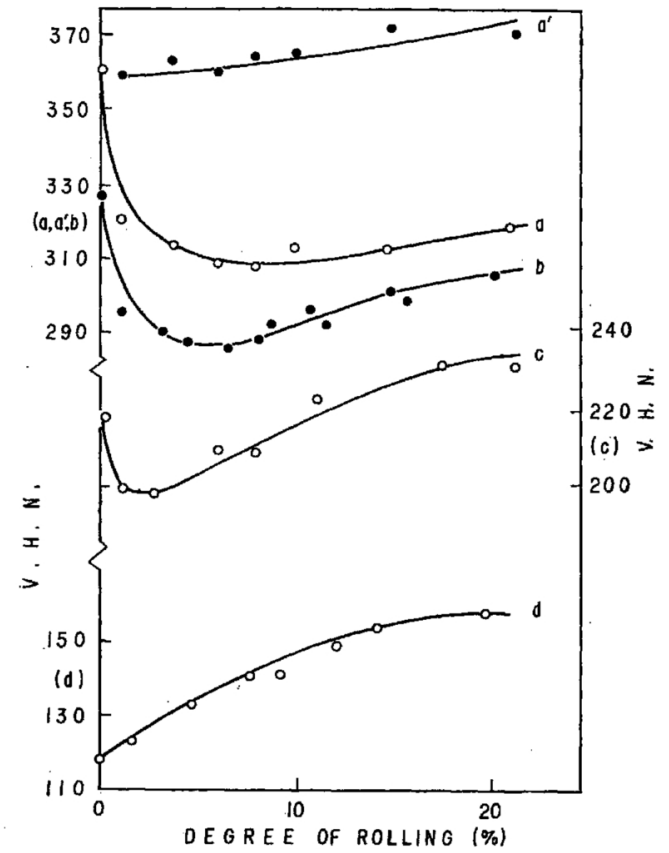

Fig. 10 Work softening curves of tempered $0.9 \% \mathrm{C}$ steel. $\mathrm{a}, \mathrm{a}^{\prime}: 450^{\circ} \mathrm{C} \times 1 / 2 \mathrm{hr}$. tempered

b : $550^{\circ} \mathrm{C} \times 1 / 2 \mathrm{hr}$. tempered

c : $700^{\circ} \mathrm{C} \times 2 \mathrm{hrs}$ tempered.

d : $725^{\circ} \mathrm{C} \times 60$ hrs. tempered

softening in the earlier stages of cold working becomes marked as the tempering temperature is lowered. Such a softening can hardly be observed in the case of a coarse globular pearlitic structure. After a specimen undergoes work softening (curve (a)), it is hardened by annealing at $300^{\circ} \mathrm{C}$ for 5 minutes nearly up to the value before cold rolling, as shown by curve $\left(a^{\prime}\right)$.

Fig. 11 gives the relation of the total surface area of cementite particles per unit volume of specimens

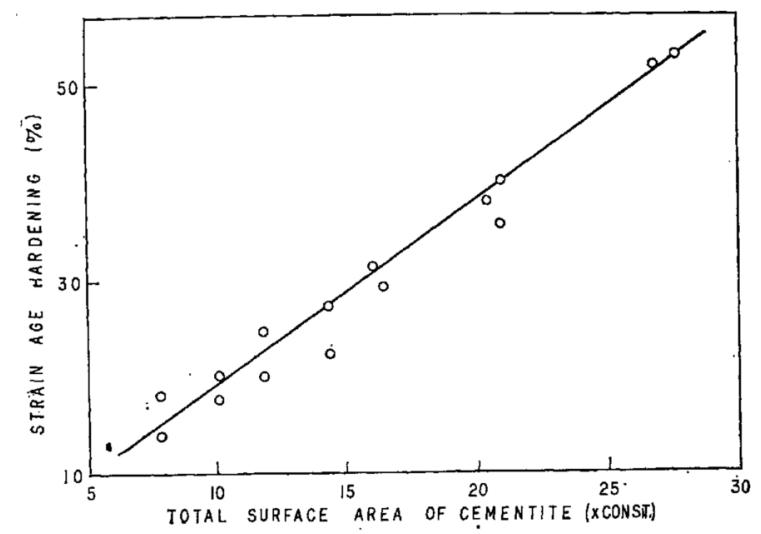

Fig. 11 Secondary strain age hardening and size of cementite particles in $0.9 \% \mathrm{C}$ steel tempered and then $10 \%$ rolled.

versus the degree of secondary strain age hardening in a $0.9 \% \mathrm{C}$ steel tempered in the range of $550^{\circ}$ to $720^{\circ} \mathrm{C}$ and then $10 \%$ rolled. Here, the total surface area was calculated from the number of particles per unit length of specimens detected under a microscope. If the number of the particles per unit length of 
specimens is $n$, and the volume fraction of the particles in specimens $f$, then the mean size of particle $c_{1} f^{1 / 3} n^{-1}$, is inversely proportional to the total surface .area above stated $c_{2} f^{2 / 3} n$. Here, $c_{1}$ and $c$ : are constant. Within the range of measurements the degree of the secondary strain age hardening increases linearly with the increase of total surface area, it probably following that this degree is proportional to the total surface area and inversely proportional to the particle size by maintaining the volume fraction of particle constant.

Carbon steels tempered at higher temperatures undergo discontinuous yielding, while those at lower temperatures do $\operatorname{not}^{(4)}$. In addition, it was confirmed from the experiments on the relation between the tensile stress-strain relationship and the work softening of a tempered $0.9 \% \mathrm{C}$ steel that there was nothing anomalous about this relationship corresponding to the work softening, but the tensile stress increased progressively from the start of the straining. How-ever, the inelastic effect in the reverse direction was very marked, that is, inelastic effect $\lambda_{1} / \lambda_{0}$ at $0.1 \%$ strain of pre-tension obtained in a similar manner to the case of Fig. 9 in the authors previous paper, was $0.50,0.58$ and 0.69 for the specimens tempered at $700^{\circ}, 650^{\circ}$ and $450^{\circ} \mathrm{C}$ for 30 minutes respectively, indicating that the inelastic effect is very marked and thus the work softening effect is also directional. In accordance, it is inferred that the work softening after tempering is the same in cause as that after secondary strain age hardening. Judged from the results on density ${ }^{(5)}$, the effect of dislocation density in tempered carbon steels on the work softening must probably be considered similarly to the case of cold working. This will be discussed later.

\section{Consideration}

1. With reference to the secondary strain age hardening in the range $150^{\circ}$ to $350^{\circ} \mathrm{C}$ of cold worked carbon steels, various peculiar results were obtained as following.

(1) Nearly no rise of yield stress corresponding to the hardening could be detected upon measuring under a stress the same in kind and direction as those of prior working. The degree of the strain age hardening is anisotropic on measuring under unidirectional stress.

(2) The hardening is chiefly associated with the dispersion of cementite particles as an obstacle against dislocation unlike the primary hardening below $150^{\circ} \mathrm{C}$. Alumina dispersed iron or copper shows a marked hardening exactly similar to that of carbon steel. Therefore, the dispersion of fine particles may contribute to the hardening.

(3) Hardening is brought about not only by low temperature annealing but by mechanical treatment such as secondary working of a different mode from the primary. In other words, it does not necessarily

(4) H. Muir, B. L. Averbach and M. Cohen: Trans. ASM, 47 (1955), 380.

(5) K. Nishino: J. Japan Inst. Metals., 24 (1960), 514, 518. need annealing. Hence, it concerns a dislocationdislocation interaction.

(4) The characteristics of the hardening are closely similar to those of $\alpha$-brass, it being desirable to explain both hardenings by a common mechanism.

Besides, the $\mathrm{X}$-ray line broadening of ferrite due to cold working becomes marked with increasing carbon content in carbon steels, and its recovery proceeds considerably by annealing in the temperature range of hardening(6). It is likely that an alloy showing remarkable strain age hardening is generally pronounced in line broadening after cold working.

2. As stated with reference to Fig. 11, the degree of secondary strain age hardening is proportional to the total surface area of cementite particles per unit volume of specimens, and inversely proportional to the mean size of particles when the volume fraction of cementite is constant. The back stress $\sigma$ originated in pile-up dislocations around particles is estimated from the following equations proposed by Fisher et $\mathrm{al}^{(7)}$,

$$
\text { or } \quad \begin{aligned}
\sigma & =3 \mu(r / s)^{3}(N b / r) \\
& =3 \mu f^{3 / 2}(N b / r)
\end{aligned}
$$

where, $\mu$ is the modulus of rigidity, $r$ is the average diameter of particles, $s$ is the particle spacing, $N$ is the number of the loops accumulated around one particle, $b$ is the Burgers vector, $f$ is the volume fraction of particle in matrix plus particle. Since the back stress is inversely proportional to $r$ by maintaining $f$ and $N$ constant, it may follow from the results of Fig. 11 that the back stress has a linear relation with the degree of secondary strain age hardening, and thus the higher the back stress the larger the secondary strain age hardening. As reported in a previous paper, the degree of inelastic effect measured during unloading after deformation behaves with the increase of degree of cold working or carbon content

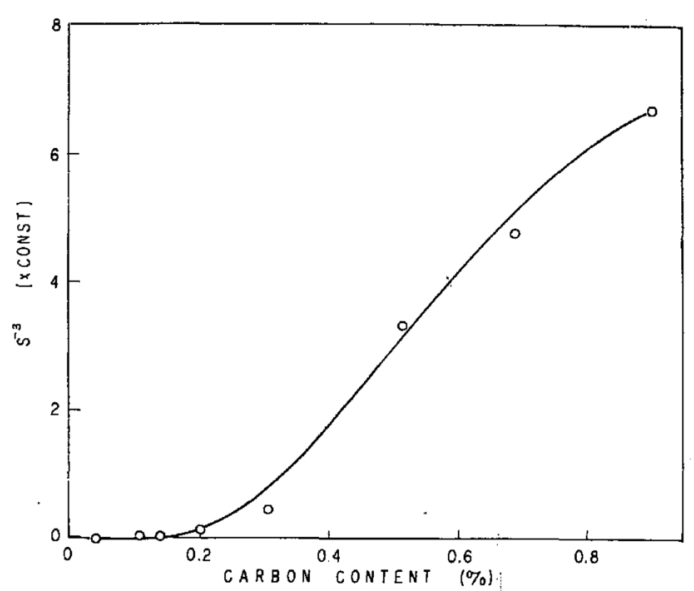

Fig. 12 Mean distance between cementite particles (S) and carbon content in carbon steels.

in carbon steels similar to that of strain age hardening measured after low temperature annealing. In addition, the secondary work hardening is the same kind as

(6) F. H. Andrew and H. Lee: J. Iron Steel Inst., 165(1950), $149,369$.

(7) J. C. Fisher, E. W. Hart and R. H. Pry : Acta Met., 1 (1953), 336. 
strain age hardening. These may lead to the presumption that the strain age hardening is related with a distribution and a rearrangement of pile-up dislocations around particles.

In the above equation, if $r$ is constant the back stress is inversely proportional to $s^{3}$. Fig. 12 shows the relation of the mean particle spacing and the carbon content in carbon steel obtained for the same specimens as shown in Fig. 2 of a previous paper. Here, the particle spacing was calculated from the number of particles per unit length of the steels. The shape of the curve is approximately analogous to those of inelastic effect and secondary strain age hardening in Fig. 2 in the previous paper. As these results refer to carbon steels of the lamellar type, the distribution of cementite is non-uniform, and it may be unappropriate to treat them similarly to the case of tempered steels. But at least it is certain that the degrees of strain age hardening and inelastic effect are affected by the dispersion of particles. In regard to the effect of the shape of the particle, Underwood et al. ${ }^{(8)}$ reported that a platelike particle is more effective as a barrier against dislocation than a globular particle, this being probably supported from the results of Figs. 4 and 8 in a previous paper. Since the level of back stress depends also on the critical stress for yielding of the particle or surrounding material, there may be a maximum peculiar to alloys. In the earlier stages of deformation, the back stress increases rapidly with the increase of strain. Once the maximum is attained on continued deformation, the degrees of inelastic effect and strain age hardening may reach to a constant value. The results on carbon steels with reference to Fig. 4 in the previous paper may be explained in such a manner.

3. Cementite particles act as a strong barrier against dislocation during deformation, causing a number of pile-up groups. Dislocations in the groups are, when unloaded, easy to move back under the influence of the back stress. Bauschinger and inelastic effects seem to be due to the presences of such a mobile dislocation and back stress. The mechanism for the hindrance of motion back must be considered from the standpoint of dislocation-location interaction. A locking of dislocations by solute atoms is considered to be rather insignificant for the reason previously stated. One possible mechanism is such that dislocations in pile-up groups move back under the influence of back stress, and encounter other groups with which they react, so that they lose mobility. Such an interaction of intersecting dislocations ${ }^{(9)}$ may be the easier and the larger the more the groups. The activation energy for the interaction $W$ is appreciably high, but it may become small in the form $W-\alpha \sigma$ because of the presence of back stress $\sigma$.

4. Copper solid solution alloys show remarkable Bauschinger and elastic after effects, and also strain age hardening in the temperature range of $100^{\circ} \sim$ $300^{\circ} \mathrm{C}^{(3)}$, these being similar to those of higher carbon steels. In $\alpha$ - $\mathrm{Cu}-\mathrm{Zn}$ and $\alpha$-Cu-Al alloys of relatively high

(8) E. K. Underwood, L. L. Marsh and G. K. Manning : Trans. AIME., 209 (1957), 1182.

(9) H. K. Birmbaum: Acta Met., 9 (1961), 320. solute concentrations, there is a sudden increase in the degree of strain age hardening beyond a particular work degree with the progress of cold working, i.e., about $15 \%$ of rolling. Such an increase can also be observed in the appearance of strain marking(3)(10). and in the changes in density, thermoelectric force: and inelastic effect ${ }^{(3)}$. Thus, it is felt that beyond. this working degree increase abruptly the obstacles. against dislocation corresponding to the particle in two phase alloy. In other words, the obstacle exists. beforehand in a two-phase alloy, whereas in a one-phase alloy it generates during cold working. Further it is. presumed that there is no essential difference between the strain age hardenings of both alloys. With reference to the obstacle in copper solid solution alloys, it. is considered that Lohmer-Cottrell type sessile dislocation is one of the strong barriers. This will be: discussed later in the reports on the strain age hardenings of austenitic Ni-Cr steels and aluminium alloys.

The presence of strong barriers may create many pile-up dislocations during deformation. Strain age hardening is generally remarkable in alloys of high dislocation density or high probability of deformation faulting, such as $\alpha-\mathrm{Cu}-\mathrm{Zn}{ }^{(11)}$ and $\alpha-\mathrm{Cu}-\mathrm{Al}^{(12)}$ alloys. and austenitic $\mathrm{Ni}-\mathrm{Cr}$ steels ${ }^{(13)}$. These alloys also. exhibit remarkable strain age hardening ${ }^{(3)(14)}$.

The degree of strain age hardening in copper solid solution alloys depends largely on the solute concentration $^{(3)(15)}$. The degrees of strain age hardening and inelastic effect become steeply large beyond a certain solute concentration, that is, beyond about $10 \% \mathrm{Zn}$ and $3 \% \mathrm{Al}$ in $\mathrm{Cu}-\mathrm{Zn}$ and $\mathrm{Cu}-\mathrm{Al}$ alloys, respectively. Such a concentration dependency is also apparent in the degree of secondary work hardening ${ }^{(3)}$ and the deformation faulting probability ${ }^{(12)}$, it being probably explained by that Lohmer-Cottrell type sessile dislocation as a barrier is the stronger the more the width of stacking fault, which increases generally with the increase of solute concentration. Further it is presumed that the principal effect of solute on strain age hardening is to form a strong barrier against dislocation and to produce many pile-up dislocations during cold working, rather than to take short range ordering or to segregate into stacking faults during low temperature annealing, and thus. that strain age hardening is common to one phase alloys including pure metals and two phase alloys. These will be discussed in detail in later reports.

In $\alpha$-brass, the degree of strain age hardening varies. widely with the kind of cold working (3). Namely, the kinds of cold working in the descending order of the degree of strain age hardening was, (1) drawing, (2) rolling, (3) compression, (4) tension. While in carbon steel, its effect is much less(5). These may be ex-

(10) L. E. Samuel : J. Inst. Metals, 83 (1954-55), 359.

(11) B. E. Wanen and E. P. Warekois : Acta Met., 3 (1955), 473.

(12) K. Nakajima : Trans. Japan Inst. Metals, 2 (1961), 21.

(13) M. J. Whelan and P. B. Hirsch : Proc. Roy. Soc., A 240 (1957), 524.

(14) K. Nishino: To be published.

(15) B. Jaoul and D. Gonzarez : Compt. Rend., 248 (1958), 2066. 
plained that in $\alpha$-brass the generation of obstacles during deformation is affected by the type of applied :stress or by the magnitude of the friction between the cold worked specimen surface and the tool, judging from the appearance of strain marking, whereas in carbon steel, the obstacle exists beforehand.

\section{Conclusion}

Secondary strain age hardening of carbon steels in the range of $150^{\circ}$ to $350^{\circ} \mathrm{C}$ was studied and the conclusions obtained are as follows.

(1) A slight application of secondary working differing in mode from the primary, causes a considerable hardening, say, secondary work hardening. The increase in hardness seems to be brought about not only by low temperature annealing but by mechanical treatment.

(2) When tempered carbon steel is cold worked slightly, softening occurs. With tempered carbon steels the degree of strain age hardening is proportional to the total surface area of cementite particles dispersed in the unit volume of the steel, and also to the level of back stress induced by pile-up dislocations around particles.

(3) Cementite particles in carbon steels act as an obstacle against dislocation during deformaton and cause stress concentration. Pile-up dislocations around particles bring about back stress, its level being chiefly dependent on particle size and spacing or its volume fraction. The strain age hardening is considered to concern a dislocation-dislocation interaction. One possible mechanism is such that dislocations in pile-up groups move back under the influence of back stress and encounter other groups with which they react, losing their mobility.

(4) The strain age hardening of carbon steel is closely similar to that of $\alpha$-brass in many respects, both hardenings being considered to be the same in cause. However, they are dissimilar only in that in the former the cementite particles act as an obstacle, while in the latter such an obstacle is formed during deformation.

In conclusion, the author wishes to express his sincere thanks to Dr. T. Sato, President of Nagoya Technical University, Nagoya, Japan, also to Dr. S. Koda and Dr. Y. Imai, Professors of Tohoku University, Sendai, Japan, all of whom kindly guided the course of this investigation. His thanks are also due to members of the Subcommittee for "Anomalies in Solid Solution of Copper Alloys" of the Japan Institute of Metals, for their helpful discussions and suggestions, and to $T$. Suzuki, T. Tsukada for their valuable assistance. 